\title{
A minimally invasive right ventricular assist device insertion late after a continuous-flow left ventricular assist device implantation
}

\author{
Masahiko Ando, MD, PhD, MPH, Takayama Hiroo, MD, PhD, Yoshifumi Naka, MD, PhD, and
}

Koji Takeda, MD, PhD, New York, NY

\author{
From the Division of Cardiac Surgery, Columbia University Medical Center, New York, NY. \\ Disclosures: Y.N. has received consulting fees from St Jude Medical/Thoratec Corp. All other authors have \\ nothing to disclose with regard to commercial support. \\ Received for publication April 26, 2017; revisions received June 6, 2017; accepted for publication July 14, 2017; \\ available ahead of print Sept 7, 2017. \\ Address for reprints: Koji Takeda, MD, PhD, Columbia University Medical Center, 177 Fort Washington Ave, \\ New York, NY 10032 (E-mail: kt2485@cumc.columbia.edu). \\ J Thorac Cardiovasc Surg 2018;155:e41-3 \\ $0022-5223 / \$ 36.00$ \\ Copyright (c) 2017 by The American Association for Thoracic Surgery \\ http://dx.doi.org/10.1016/j.jtcvs.2017.07.066
}

Video clip is available online.

Right heart failure (RHF) after left ventricular assist device (LVAD) implantation is an unresolved issue associated with mortality and morbidity. ${ }^{1}$ Although temporary right ventricular assist devices (RVADs) are useful for severe RHF in the acute phase, recent studies raise issues in RVAD for late RHF. Redo sternotomy often is too invasive for particularly sick patients with chronic venous congestion. Technology has enabled us to apply percutaneous RVADs via the internal jugular vein (IJV) or femoral vein; however, these options are limited for patients' motility and access issues, such as thrombosis or obstruction. This report presents our unique RVAD through a minithoracotomy in patients with late RHF.

A 61-year-old man with a history of hypertension, diabetes, and chronic kidney disease on hemodialysis, and who received coronary artery bypass grafting underwent HeartMate II (Thoratec Corporation, Pleasanton, Calif) implantation at an outside hospital. The patient had RHF postoperatively, requiring long-standing inotropic therapy. Two months after LVAD, the patient again developed severe RHF with a central venous pressure of $36 \mathrm{~mm} \mathrm{Hg}$ and acute kidney injury. He was initially placed on a percutaneous RVAD using a dual-lumen cannula through IJV $^{2}$ and continuous veno-veno hemofiltration (CVVH). After 9 days, superior vena cava syndrome developed, and the percutaneous RVAD had to be removed. He was transferred to our institution for further management. At admission, his central venous pressure was $23 \mathrm{~mm} \mathrm{Hg}$ with a wedge pressure of $19 \mathrm{~mm} \mathrm{Hg}$. He was receiving dual inotropes

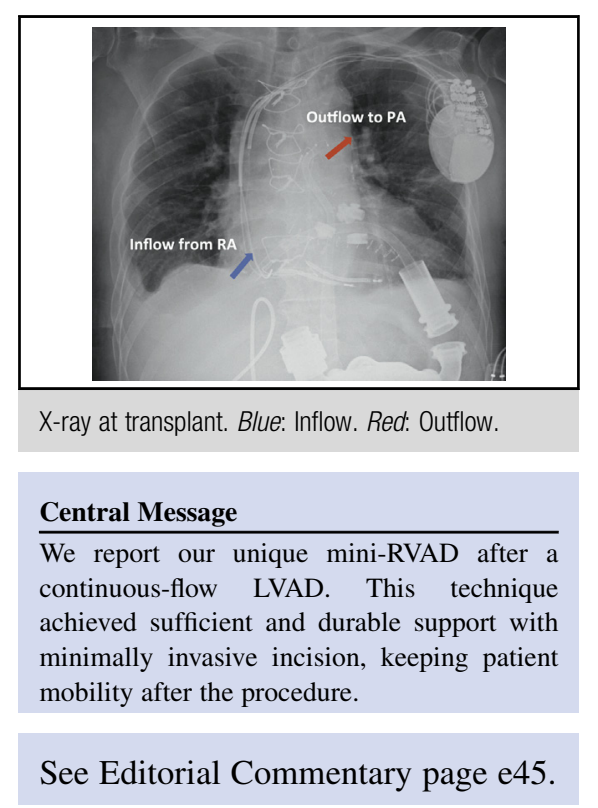

and CVVH. Ultrasound revealed an occlusion of bilateral IJVs. For his RHF, an Impella RP (Abiomed, Danvers, Mass) was inserted from the femoral vein. One day later, he was weaned from CVVH (Figure 1). After multiple

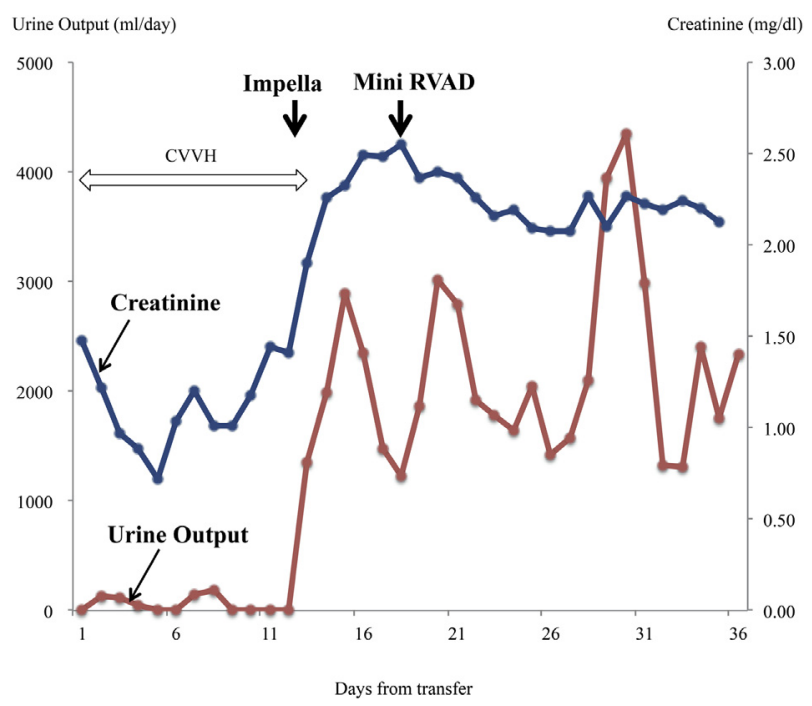

FIGURE 1. Renal functions from the day of transfer. $C V V H$, Continuous veno-venous hemodialysis; mini-RVAD, minimally invasive right ventricular assist device. 


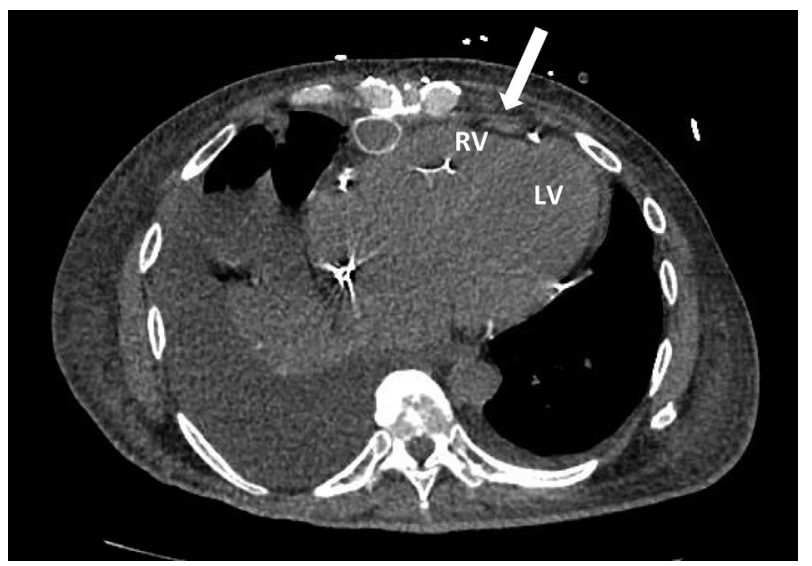

FIGURE 2. Chest computed tomography. White arrow indicates the approach. $L V$, Left ventricle; $R V$, right ventricle.

failures of weaning from the Impella device, we decided to advance support using the CentriMag device (Thoratec Corporation). To avoid redo sternotomy and overcome access issues, we applied an RVAD insertion via the right ventricular (RV) surface. Chest computed tomography was useful for planning (Figure 2, Video 1).

With single-lumen intubation, a 4-cm incision was made above the fourth intercostal space. The right ventricle outflow was exposed, and 2 sets of 3-0 double mattress sutures with bovine pericardium pledgets were placed on the RV. A guidewire was introduced into the main pulmonary artery under fluoroscopy. Another guidewire was introduced into the inferior vena cava. A 17F Biomedicus (Medtronic, Dublin, Ireland) arterial cannula was inserted into the PA, and a 23F Biomedicus arterial cannula was inserted into the right atrium (Figure 3). Both cannulas were connected, and the RVAD was actuated. Four liters of flow were obtained. The Impella device was removed. Postoperatively, he

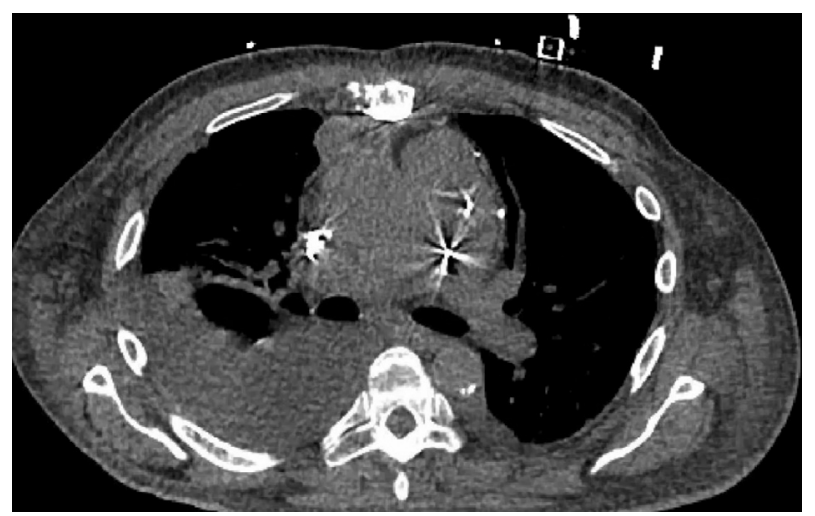

VIDEO 1. Chest computed tomography. Video available at: http://www. jtcvsonline.org/article/S0022-5223(17)31719-1/fulltext.

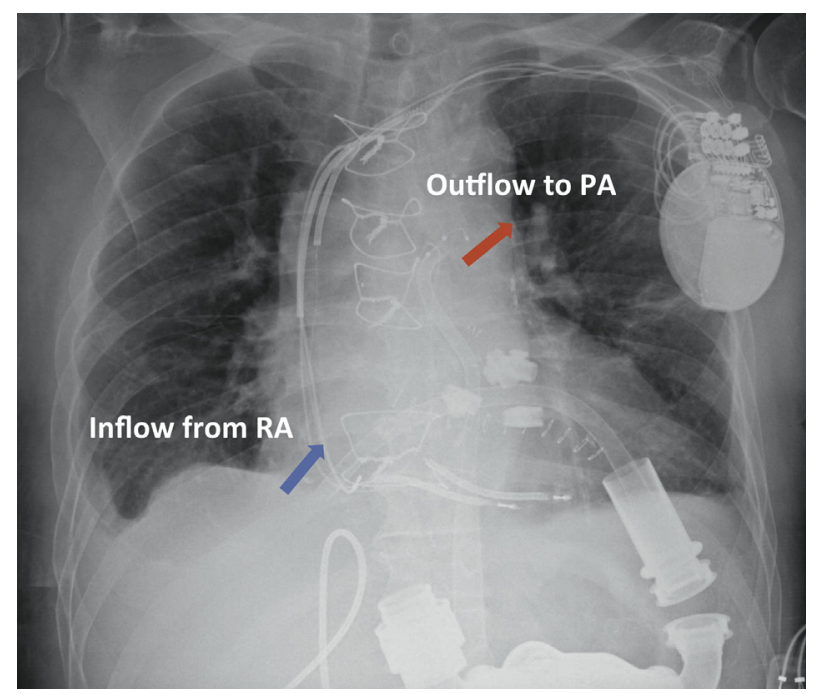

FIGURE 3. X-ray at transplant. Blue: Inflow. Red: Outflow. RA, Right atrium; $P A$, pulmonary artery.

was weaned from CVVH and inotropes. He recovered until he could walk with this biventricular support. Figure 1 shows his renal function recovery. Three months after this RVAD implantation, he underwent transplantation. During dissection, we confirmed that both cannulas were securely attached to the right ventricle with no signs of infection or dislodgement.

This is a report of our unique mini-RVAD for a patient with severe late RHF. We were able to safely bridge the patient until transplantation, and our attempt not only achieved abundant flow to allow weaning from CVVH and inotropes but also kept the patient's mobility in preparation for transplant, with minimal invasion.

We previously reported late RHF occurrence after LVAD insertion is $11 \%$, and $10 \%$ of those who had late RHF eventually required RVAD. ${ }^{3}$ However, even today, there is no standard approach for late RHF occurring later than 4 weeks after LVAD. Our goals of mechanical support for late RHF would be sufficient flow, minimal invasion, and patient mobility, and there are few options. Central cannulation with redo sternotomy always is the choice but could be too invasive, particularly in patients with long-standing venous congestion. Percutaneous RVAD would be another option after LVAD. We currently use the Tandem heart with a Protek-Duo cannula (CardiacAssist Inc, Pittsburgh, Pa) through the $\mathrm{IJV}^{2}$ but for this patient that option was not feasible because of the superior vena cava syndrome. The Impella RP is another noninvasive option, ${ }^{4}$ but patient motility and durability of support are obvious issues. In this sense, our miniRVAD is a useful option for patients requiring sufficient and durable support and mobilization after the procedure. With appropriate guidewire techniques under fluoroscopy, cannulation from the right ventricle under limited 
exposure was safe and smooth. Our initial concern was an adhesion during transplant, which was not as tight as expected.

\section{References}

1. Takeda K, Takayama H, Colombo PC, Jorde UP, Yuzefpolskaya M, Fukuhara S, et al. Late right heart failure during support with continuous-flow left ventricular assist devices adversely affects post-transplant outcome. J Heart Lung Transplant. 2015;34:667-74
2. Schmack B, Weymann A, Popov AF, Patil NP, Sabashnikov A, Kremer J et al. Concurrent left ventricular assist device (LVAD) implantation and percutaneous temporary RVAD support via CardiacAssist Protek-Duo TandemHeart to preempt right heart failure. Med Sci Monit Basic Res. 2016 22:53-7.

3. Takeda K, Takayama H, Colombo PC, Yuzefpolskaya M, Fukuhara S, Han J, et al. Incidence and clinical significance of late right heart failure during continuousflow left ventricular assist device support. J Heart Lung Transplant. 2015;34: 1024-32.

4. Morgan JA, O'Neill WW. Percutaneous right ventricular assist device support in a patient supported by an LVAD. ASAIO J. 2016;62:e41-2. 